\title{
Analysis of Dynamic Stability of Planing Craft on the Vertical Plane
}

Roberto Algarín ${ }^{1}$

Oscar Tascón ${ }^{2}$

\begin{abstract}
A dynamic model for the motion of planing craft on the vertical plane was developed; the motions of surge, heave, and pitch are coupled. Critical conditions that produce the inception of instability are evaluated. The Wagner model (1932) for 2D impact is extended for section with knuckles. Planing hulls were analyzed through the application of slender body theory. The results are compared with Tveitnes (2001), Peterson (1997), Savitsky (1964), Troesch (1992) and Celano (1998).
\end{abstract}

Key words: Slamming, Porpoising, planing boats, dynamic stability.

\section{Resumen}

Se desarrolla un modelo dinámico del movimiento de embarcaciones de planeo en el plano vertical acoplando los movimientos de avance y levantamiento, cabeceo. Se determinan las condiciones críticas que dan origen de la inestabilidad. El modelo de Wagner (1932) para el impacto 2D es extendido para secciones con codillos. Mediante la aplicación de la teoría de cuerpos esbeltos se analizan las embarcaciones de planeo. Los resultados obtenidos son comparados con Tveitnes (2001), Peterson (1997), Savitsky (1964), Troesch (1992), Celano (1998).

Palabras claves: impacto en el agua, botes de planeo, estabilidad dinámica.

Date Received: January 22th, 2013 - Fecha de recepción: 22 de Enero de 2013

Date Accepted: March 6th, 2013 - Fecha de aceptación: 6 de Marzo de 2013

${ }^{1}$ COTECMAR. Research, Development, and Innovation Department. Cartagena, Colombia. e-mail: algarinr@cotecmar.com.co
${ }^{2}$ COTECMAR. Research, Development, and Innovation Department. Cartagena, Colombia. e-mail: otascon@cotecmar.com.co 


\section{Introduction}

Wagner (1932) developed an analytic model to predict pressure distribution in the impact with symmetry entry. Fig. 1 shows a wedge section with symmetry entry, where $b$ is the beam of the section, $d$ is the keel-knuckle distance, $\beta$ is the dead rise angle, $y$ and $z$ are the horizontal and vertical axis, respectively.

Fig. 1. Wedge section impact with symmetry entry

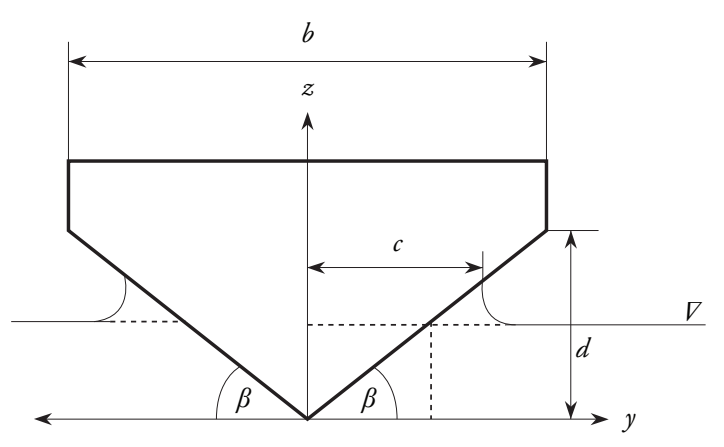

For this kind of section, pressure distribution is evaluated as:

$$
\frac{P}{\rho}=\dot{w} \sqrt{c^{2}-y^{2}}+\frac{\dot{w} c c}{\sqrt{c^{2}-y^{2}}}-\frac{w^{2}}{2} \frac{y^{2}}{c^{2}-y^{2}}
$$

Where $\rho$ is the fluid density, $P$ is the pressure, $c$ is the wetted half-beam, $w$ is the vertical velocity, $\dot{c}$ is the time variation of the half-beam, which is evaluated as:

$$
\dot{c}=\frac{\pi}{2} \frac{w}{\tan \beta}
$$

\section{D Impact}

The Wagner model (1932) does not work after the flow separation from the knuckle, for this case the boundary condition $\mathrm{P}=0$ on $\mathrm{y}=\mathrm{b} / 2$ is applied, thus:

$$
\frac{P}{\rho}=\dot{w} \sqrt{c^{2}-\left(\frac{b}{2}\right)^{2}}+\frac{w c \dot{c}}{\sqrt{c^{2}-\left(\frac{b}{2}\right)^{2}}}-\frac{w^{2}}{2} \frac{\left(\frac{b}{2}\right)^{2}}{c^{2}-\left(\frac{b}{2}\right)^{2}}=0
$$

When the section is moved with constant velocity $\dot{w}=0$, replacing

$$
\dot{c}=\frac{w^{2}}{2} \frac{\left(\frac{b}{2}\right)^{2}}{c \sqrt{c^{2}-\left(\frac{b}{2}\right)^{2}}}
$$

The variables are separated and integrated, the virtual half-beam wetted after the flow separation is:

$$
c=\sqrt{\left(\frac{b}{2}\right)^{2}+\left[\frac{3}{2}\left[w\left(\frac{b}{2}\right)^{2}\left(t-t_{0}\right)\right]\right]^{2 / 3}}
$$

Where $c$ is the half-beam in the instant, $t$, and $t_{0}$ is the time when the flow is on the knuckle.

\section{D Dynamic Impact}

The total force in the section is:

$$
f_{z}=f_{H D}+f_{H s}+f_{v}
$$

Where $f_{H D}$ is the hydrodynamic force, $f_{H S}$ is the hydrostatic force and $f_{v}$ is the sectional drag force. By integrating equation 1 the hydrodynamic force in the section is obtained:

$$
\begin{aligned}
f_{H D}=\rho \dot{w} \int_{-y 1}^{y 1} & \sqrt{c^{2}-y^{2}} d y \\
& +\rho \dot{w} \int_{-y 1}^{y 1} \frac{c \dot{c}}{\sqrt{c^{2}-y^{2}}} d y \\
& -\rho \frac{w^{2}}{2} \int_{-y 1}^{y 1} \frac{y^{2}}{c^{2}-y^{2}} d y
\end{aligned}
$$

$f_{H D}=-\dot{w} m_{a}+f_{H D}$

Where

$$
\begin{aligned}
m_{a}= & \rho \int_{-y 1}^{y 1} \sqrt{c^{2}-y^{2}} d y \\
f_{H D}^{\prime}= & \rho \dot{w} \int_{-y 1}^{y 1} \frac{c \dot{c}}{\sqrt{c^{2}-y^{2}}} d y \\
& -\rho \frac{w^{2}}{2} \int_{-y 1}^{y 1} \frac{y^{2}}{c^{2}-y^{2}} d y
\end{aligned}
$$


Fig. 2. Forces in the section

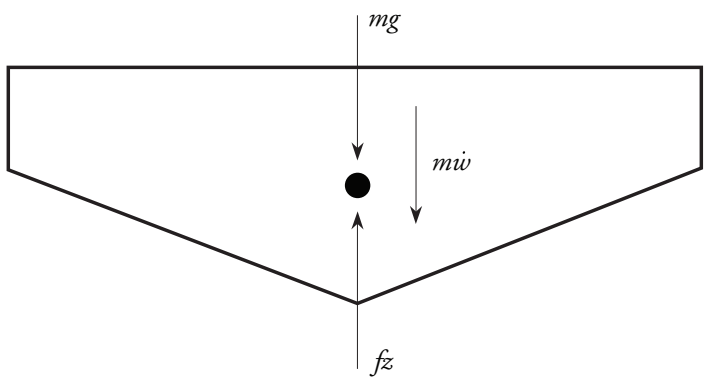

Fig. 2 shows the forced in the section. The equilibrium of forces in the section is:

$$
\sum f_{z}=\dot{w} m_{a}+f_{H D}^{\prime}+f_{H S}+f_{v}-m g=-m \dot{w}
$$

Replacing

$$
f_{z}^{\prime}=f_{H D}^{\prime}+f_{H S}+f_{v}
$$

The hydrostatic force is calculated as:

$$
f_{H S}=\rho g A_{0}
$$

Where $g$ is the gravity constant and $A_{0}$ is the immersed area, the drag force is calculated as:

$$
f_{v}=\frac{1}{2} \rho C_{a}\left(2 y_{1}\right) w^{2}
$$

Where $C_{d}$ is the sectional drag coefficient, which takes values of:

$$
C_{d}=\left\{\begin{array}{c}
w \geq 0, C_{d}=0.5 \\
w<0, C_{d}=-1.0
\end{array}\right\}
$$

The acceleration in the section is:

$$
\dot{w}=\frac{m g-f_{z}^{\prime}}{m+m_{a}}
$$

\section{D Impact Results}

The sectional force coefficient is defined as:

$$
C_{f}=\frac{f_{z}}{\frac{1}{2} \rho b w^{2}}
$$

Figs. 3, 4, and 5 show the results of force coefficient variation with immersion for different wedge sections; the results are compared with Tveitnes (2001) with a good agreement, the peak of force is over predicted.

Fig. $3 . \mathrm{C}_{\mathrm{F}}$ vs. $\mathrm{z} / \mathrm{d}, \mathrm{B}=10^{\circ}$

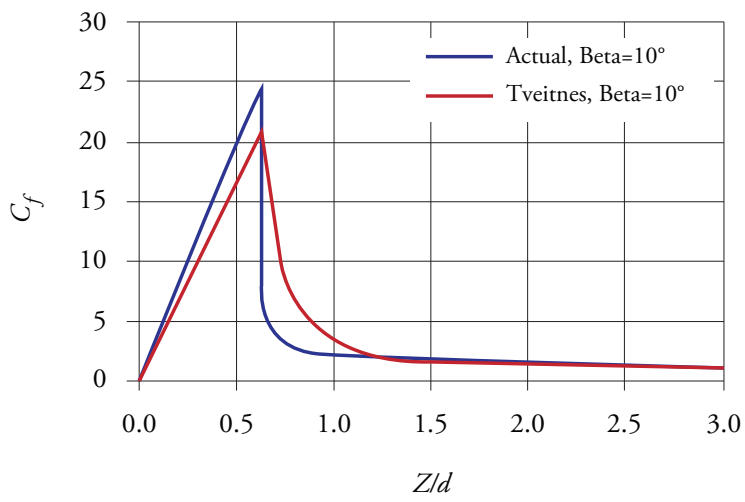

Fig. $4 . \mathrm{C}_{\mathrm{F}}$ vs. $\mathrm{z} / \mathrm{d}, \mathrm{B}=20^{\circ}$

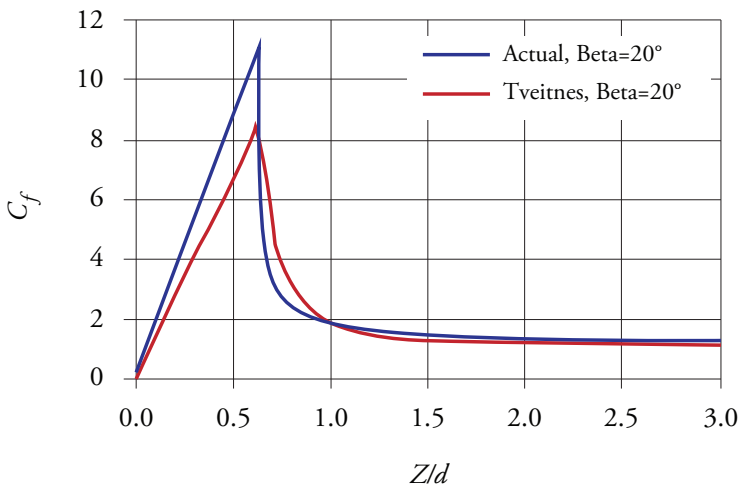

Fig. $5 . \mathrm{C}_{\mathrm{F}}$ vs. $\mathrm{z} / \mathrm{d}, \mathrm{B}=30^{\circ}$

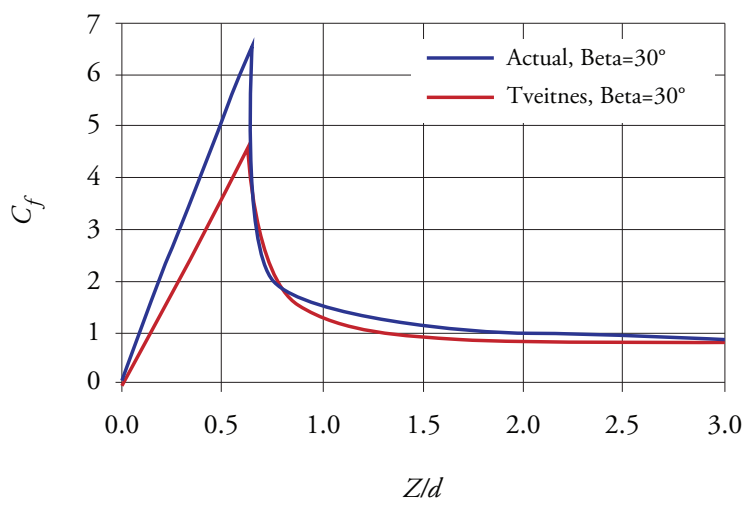


Figs. 6, 7, 8, 9, 10, and 11 show the results of acceleration with free drop; the section has the following properties: $b=2 \mathrm{ft}, \beta=20^{\circ}$, width $=8$ $\mathrm{ft}$. The initial height was varied by 2,4 , and $6 \mathrm{ft}$,

Fig. 6. Acceleration vs. time, $h=2 \mathrm{ft}, \mathrm{m}=269 \mathrm{lb}$

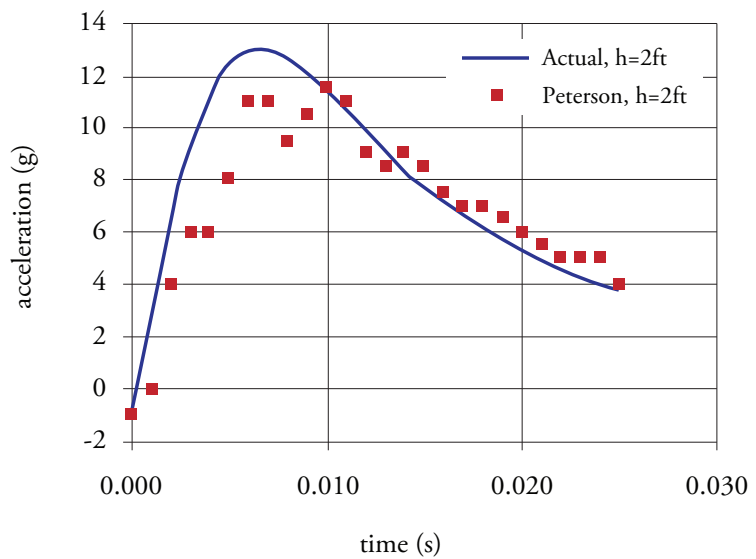

Fig. 7. Acceleration vs time, $h=4 \mathrm{ft}, \mathrm{m}=269 \mathrm{lb}$

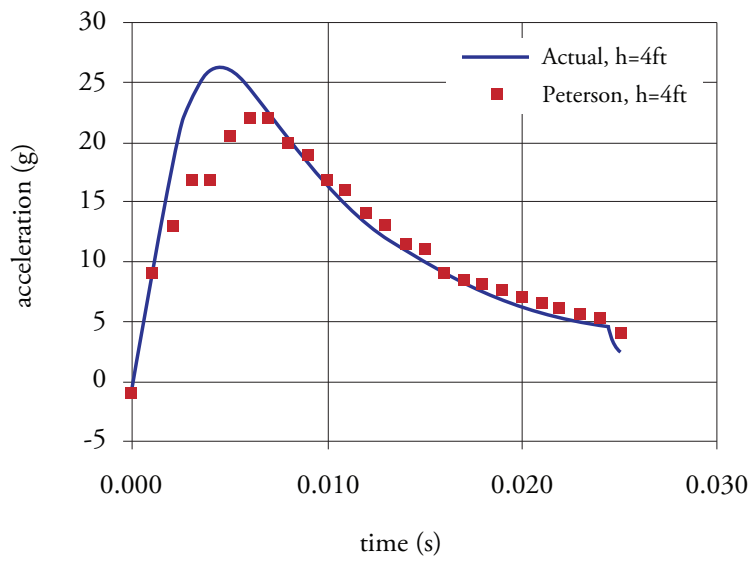

Fig. 8. Acceleration vs time, $\mathrm{h}=6 \mathrm{ft}, \mathrm{m}=269 \mathrm{lb}$

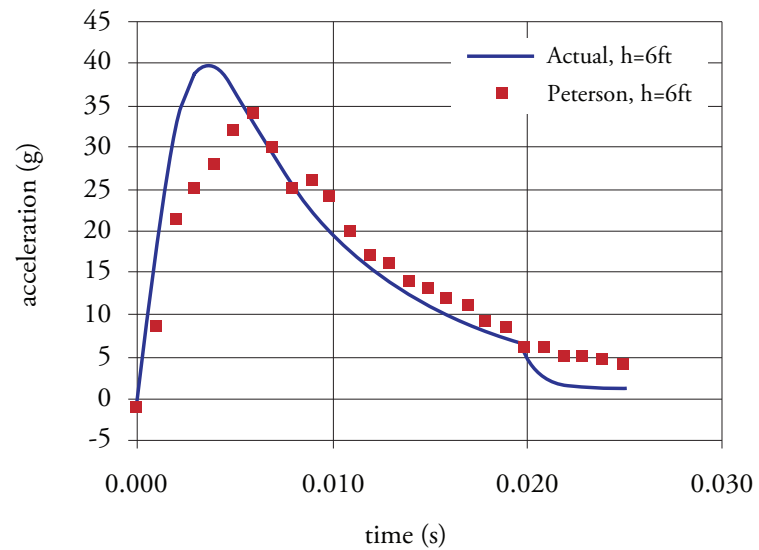

while the mass of the wedge took values of 269 and $641 \mathrm{lb}$. The results obtained are compared with Peterson (1997) with good agreement.

Fig. 9. Acceleration vs. time, $h=2 \mathrm{ft}, \mathrm{m}=641 \mathrm{lb}$

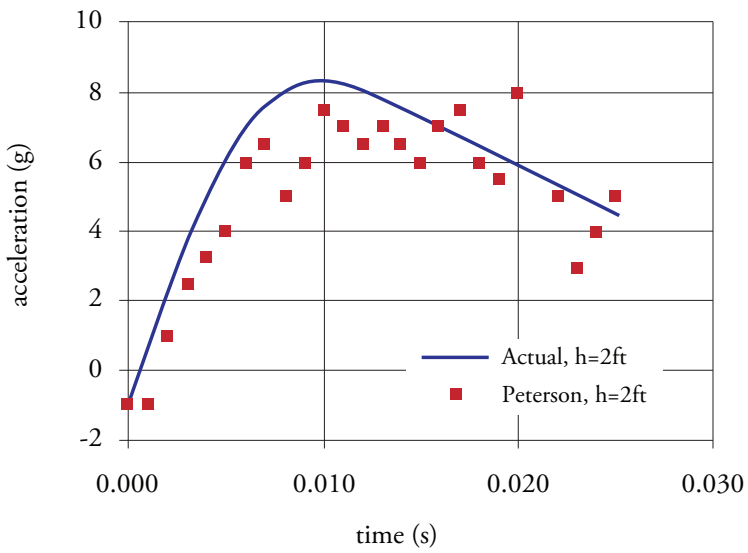

Fig. 10. Acceleration vs time, $h=4 \mathrm{ft}, \mathrm{m}=641 \mathrm{lb}$

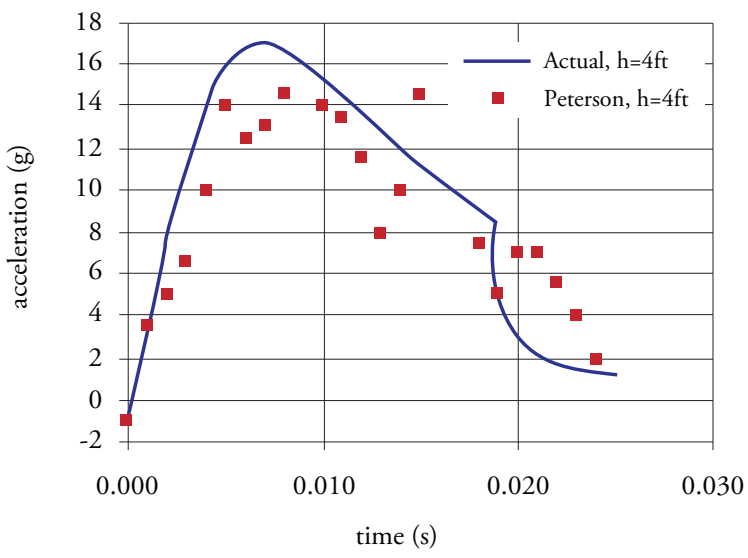

Fig. 11. Acceleration vs. time, $h=6 \mathrm{ft}, \mathrm{m}=641 \mathrm{lb}$

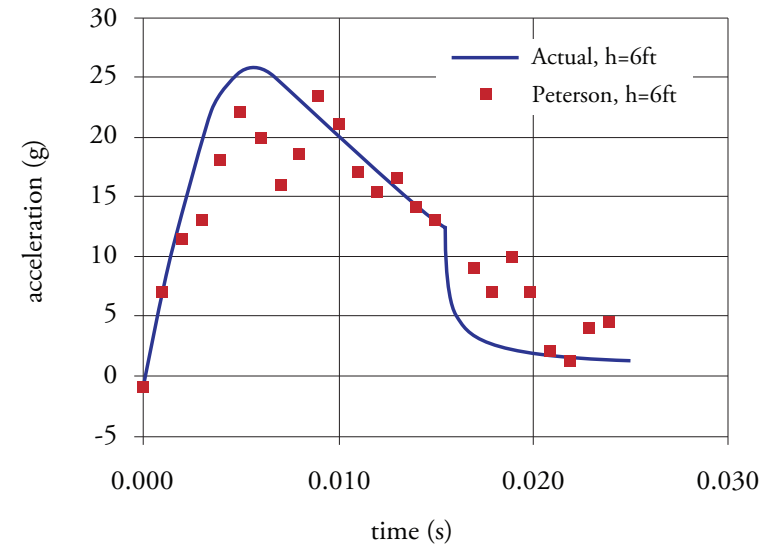




\section{Dynamic Model of Motion on the Vertical Plane of Planing Boats}

Fig. 12 shows a planing boat on calm water, $D$ is the draft in the transom, $L_{c d g}$ and $V_{c d g}$ are the horizontal and vertical position of the gravity center, $\theta$ is the trim angle, $z_{c d g}$ is the height of the center of gravity with respect to the water line, $x$ and $z$ are fixed coordinates in the boat.

$$
\begin{aligned}
& D=L_{c d g} \sin \theta+V_{c d g} \cos \theta-z_{c d g} \\
& T_{0}=D-\left(x \sin \theta+Z_{1} \cos \theta\right)
\end{aligned}
$$

Replacing

$$
T_{0}=-\left(X-L_{c d g}\right) \sin \theta+\left(V_{c d g}-Z_{1}\right) \cos \theta-z_{c d g}
$$

If $\cos \theta \approx 1$

$$
T_{0}=-\left(x-L_{c d g}\right) \sin \theta+\left(V_{c d g}-z_{1}\right)-z_{c d g}
$$

The velocity impact of each section is evaluated as:

$$
\begin{array}{r}
w=\frac{D T_{0}}{D t}=\frac{d T_{0}}{d t}-U \frac{d T_{0}}{d x} \\
\begin{array}{r}
w=-\left(x-L_{c d g}\right) \\
\cos \theta(\dot{\theta})-\dot{z}_{c d g} \\
+U\left(\sin \theta+\frac{d z_{1}}{d x}\right)
\end{array}
\end{array}
$$

By simplification

$$
\begin{aligned}
w=-\left(x-L_{c d g}\right) & (\dot{\theta})-\dot{z}_{c d g} \\
& +U\left(\sin \theta+\frac{d z_{1}}{d x}\right)
\end{aligned}
$$

Where $\dot{\theta}$ is the pitch velocity, $\dot{z}_{c d g}$ is the vertical velocity in the $c g$. The acceleration impact of each section is evaluated as:

$$
\begin{aligned}
\dot{w}= & \frac{D w}{D t}=\frac{d w}{d t}-U \frac{d w}{d x} \\
\dot{w}= & -\left(x-L_{c d g}\right)(\ddot{\theta})-\ddot{z}_{c d g}+2 U \cos \theta(\dot{\theta}) \\
& +\dot{U}\left(\sin \theta+\frac{d z_{1}}{d x}\right)-U^{2} \frac{d^{2} z_{1}}{d x^{2}}
\end{aligned}
$$

By simplification

$$
\begin{aligned}
\dot{w}= & -\left(x-L_{c d g}\right) \ddot{\theta}-\ddot{z}_{c d g}+2 U \dot{\theta} \\
& +\dot{U}\left(\sin \theta+\frac{d z_{1}}{d x}\right)-U^{2} \frac{d^{2} z_{1}}{d x^{2}}
\end{aligned}
$$

\section{Calculation of Forces in the hull}

Fig. 13 (pag. 30) shows the forces in the hull, where $T$ is the thrust, $F_{N}$ is the normal hydrodynamic force, $M_{H D}$ is the hydrodynamic moment, $\mathrm{mg}$ is the weight, $F_{v}$ is the viscous $\mathrm{drag}, \delta$ is the angle of the propulsion shaft, $d_{v}$ is the perpendicular distance between $F_{v}$ and $c g, d_{T}$ is the perpendicular distance between $T$ and $c g$.

The normal force to the keel is evaluated as:

$$
F_{N}=\int_{0}^{l} C_{t r}(x) f d x
$$

Where $l$ is the length of the boat and $c_{t r}(x)$ is the suction pressure coefficient of the transom, which is calculated as:

Fig. 12. Geometry properties in planing hull in calm water

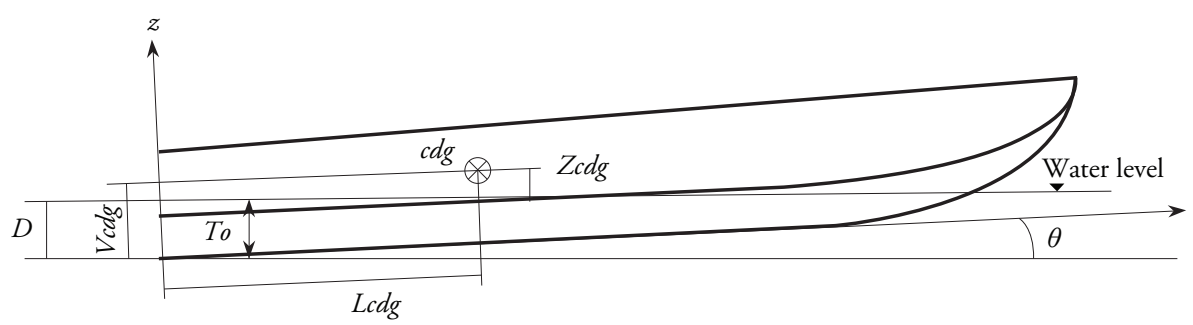


Fig. 13. Forces in the planing hull

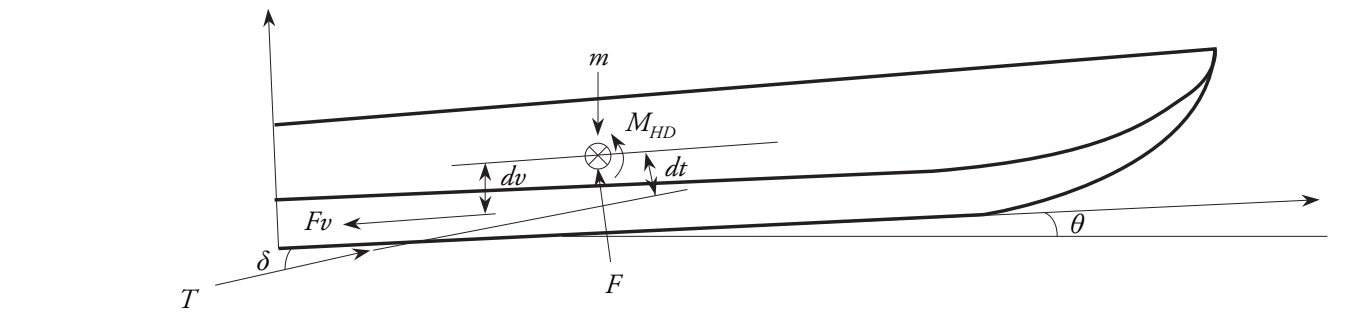

$$
c_{t r}(x)=\tan h\left(\frac{2.5}{0.34 B C_{v}} x\right)
$$

Replacing the normal force is:

$$
F_{N}=\int_{0}^{l} \dot{w} c_{t r}(x) m_{a} d x+\int_{0}^{l} c_{t r}(x) f_{z}^{\prime} d x
$$

The solution of the first integral is:

$$
\begin{aligned}
\int_{0}^{l} \dot{w} c_{t r}(x) m_{a} d x & =\int_{0}^{l}\left[-\left(x-L_{c d g}\right) \ddot{\theta}-\ddot{z}_{c d g}+2 U \dot{\theta}\right. \\
& \left.+\dot{U}\left(\sin \theta+\frac{d z_{1}}{d x}\right)-U^{2} \frac{d^{2} z_{1}}{d x^{2}}\right] \\
& c_{t r}(x) m_{a} d x \\
\int_{0}^{l} \dot{w} c_{t r}(x) m_{a} d x & =\left(M_{1} \sin \theta\right) \dot{U}-M_{1} \ddot{z}_{c d g}+2 M_{1} U \dot{\theta} \\
& -M_{2} \ddot{\theta}-\int_{0}^{l} U^{2} \frac{d^{2} z_{1}}{d x^{2}} m_{a} d x
\end{aligned}
$$

Where

$$
\begin{aligned}
& M_{1}=\int_{0}^{l} c_{t r}(x) m_{a} d x \\
& M_{2}=\int_{0}^{l}\left(x-L_{c d g}\right) c_{t r}(x) m_{a} d x
\end{aligned}
$$

By substitution

$$
F_{N}=\left(M_{1} \sin \theta\right) \dot{U}-M_{1} \ddot{z}_{c d g}+2 M_{1} U \dot{\theta}-M_{2} \ddot{\theta}+F_{N}^{\prime}
$$

Where

$$
F_{N}^{\prime}=\int_{0}^{l}-U^{2} \frac{d^{2} z_{1}}{d x^{2}} m_{a} d x+\int_{0}^{l} f^{\prime} d x
$$

The hydrodynamic moment is calculated as:

$$
M_{H D}=\int_{0}^{l}\left(x-L_{c d g}\right) c_{t r}(x) f d x
$$

$$
+\int_{0}^{l}\left(x-L_{c d g}\right) c_{t r}(x) f_{z}^{\prime} d x
$$

$$
\begin{aligned}
& \int_{0}^{l} \dot{w}\left(x-L_{c d g}\right) c_{t r}(x) m_{a} d x=\left(M_{2} \sin \theta\right) \dot{U}-M_{2} \ddot{z}_{c d g} \\
& +2 M_{2} U \dot{\theta}-M_{3} \ddot{\theta}-\int_{0}^{l} U^{2}\left(x-L_{c d g}\right) \frac{d^{2} z_{1}}{d x^{2}} c_{t r}(x) m_{a} d x
\end{aligned}
$$

Where $M_{3}$ is:

$$
M_{3}=\int_{0}^{l}\left(x-L_{c d g}\right)^{2} c_{t r}(x) m_{a} d x
$$

By substitution

$$
\begin{aligned}
M_{H D}= & \left(M_{2} \sin \theta\right) \dot{U}-M_{2} \ddot{z}_{c d g} \\
& +2 M_{2} U \dot{\theta}-M_{3} \ddot{\theta}+M_{H D}^{\prime}
\end{aligned}
$$

Where

$$
\begin{aligned}
M_{H D}^{\prime}= & -\int_{0}^{l} U^{2}\left(x-L_{c d g}\right) \frac{d^{2} z_{1}}{d x^{2}} c_{t r}(x) m_{a} d x \\
& +\int_{0}^{l}\left(x-L_{c d g}\right) c_{t r}(x) f_{z}^{\prime} d x
\end{aligned}
$$

The viscous drag force is calculated as:

$$
f_{v}=\frac{1}{2} \rho C_{a} A U^{2}
$$


$C_{f}$ is the friction coefficient, $A$ is the wetted area of the hull. The equilibrium of forces in $X$ is:

$$
\begin{aligned}
\sum F_{x}=T \sin (\theta+\delta) & -F_{N} \sin \theta \\
& -F_{v} \cos \theta=M \ddot{x}_{c d g}
\end{aligned}
$$

By replacing

$$
\begin{aligned}
T \cos (\theta+\delta)- & \left(F_{N}^{\prime}+2 M_{1} U \dot{\theta}\right) \sin \theta-F_{v} \sin \theta \\
& =\left(M+M_{2} \sin ^{2} \theta\right) \dot{U} \\
& -\left(M_{1} \sin \theta\right) \ddot{z}_{c d g}-\left(M_{2} \sin \theta\right) \ddot{\theta}
\end{aligned}
$$

The equilibrium of forces in $Z$ is:

$$
\begin{array}{r}
\sum F_{z}=F_{N} \cos \theta-F_{v} \sin \theta+T \sin (\theta+\delta) \\
-M g=M \ddot{z}_{c d g}
\end{array}
$$

By replacing

$$
\begin{aligned}
\left(F_{N}^{\prime}+2 M_{1} U \dot{\theta}\right) \cos \theta & -F_{v} \sin \theta+T \sin (\theta+\delta) \\
& -M g \\
& =-\left(M_{2} \sin \theta \cos \theta\right) \dot{U} \\
& +\left(M+M_{1} \cos \theta\right) \ddot{z}_{c d g} \\
& +\left(M_{2} \cos \theta\right) \ddot{\theta}
\end{aligned}
$$

The equilibrium of momentum in $y$ is:

$$
\sum M_{y}=M_{H D}-d_{v} F_{v}+d_{t} T=l_{y y} \ddot{\theta}
$$

By replacing

$$
\begin{aligned}
M_{H D}^{\prime}-d_{v} F_{v}+ & d_{t} T \\
& =-\left(M_{2} \sin \theta\right) \dot{U}+M_{2} \ddot{z}_{c d g} \\
& +\left(l_{y y}+M_{3}\right) \ddot{\theta}
\end{aligned}
$$

The equations of motion are coupled obtaining the following expression:

$$
\begin{gathered}
{\left[\begin{array}{ccc}
M+M_{2} \sin ^{2} \theta & M-M_{1} \sin \theta & M_{2} \sin \theta \\
-M_{1} \sin \theta \cos \theta & M+M_{1} \cos \theta & M_{2} \cos \theta \\
-M_{2} \sin \theta & M_{2} & l_{y y}+M_{3}
\end{array}\right]\left[\begin{array}{c}
\ddot{x}_{c d g} \\
\ddot{z}_{c d g} \\
\ddot{\theta}
\end{array}\right]} \\
=\left[\begin{array}{c}
T \cos (\theta+\delta)-\left(F_{N}^{\prime}+2 M_{1} U \dot{\theta}\right) \sin \theta-F_{v} \sin \theta \\
\left(F_{N}^{\prime}+2 M_{1} U \dot{\theta}\right) \cos \theta-F_{v} \sin \theta+T \sin (\theta+\delta)-M g \\
=M_{H D}^{\prime}-d_{v} a F_{v}+d_{t} T
\end{array}\right]
\end{gathered}
$$

When the velocity of the boat is constant:

$$
\begin{gathered}
{\left[\begin{array}{cc}
M+M_{1} \cos \theta & M_{2} \cos \theta \\
M_{2} & l_{y y}+M_{3}
\end{array}\right]\left[\begin{array}{c}
\ddot{z}_{c d g} \\
\ddot{\theta}
\end{array}\right]} \\
=\left[\begin{array}{c}
\left(F_{N}^{\prime}+2 M_{1} U \dot{\theta}\right) \cos \theta-F_{v} \sin \theta+T \sin (\theta+\delta)-M g \\
=M_{H D}^{\prime}-d_{v} a F_{v}+d_{t} T
\end{array}\right]
\end{gathered}
$$

\section{Results of the Application on Planing Boats}

For analysis, the following parameters are defined:

$$
\begin{aligned}
& c_{v}=\frac{U}{\sqrt{g B}} \\
& c_{\Delta}=\frac{M}{\rho B^{3}} \\
& c_{L}=\frac{F_{z}}{\frac{1}{2} \rho U^{2} B^{2}} \\
& \lambda=\frac{L_{k}+L_{c}}{2 B}
\end{aligned}
$$

Where $c_{v}, c_{\Delta}, c_{L}$ are the coefficients of velocity, load, and lift; $\lambda$ is the mean wetted length, $M$ is the displacement, $B$ is the beam of the boat, $L_{k}$ and $L_{c}$ are the wetted length of the keel and the wetted length of the chine. Figs. 14, 15, 16, and 17 show the results of forces on steady condition for a constant forward velocity, the boat has the following properties: $V_{c d g} / B=0.65, L_{c d g} / B=1.47 \theta=$ $4^{\circ}$ and $\lambda=3 . \eta_{3}$ and $\eta_{4}$ are the vertical elevation and rotation of the $\mathrm{cg}$ from the equilibrium position. The results are compared with Troesch (1992) and Savitsky (1964). 
Fig. 14. $\mathrm{F}_{\mathrm{z}}$ vs. $\eta_{3} / \mathrm{B}$

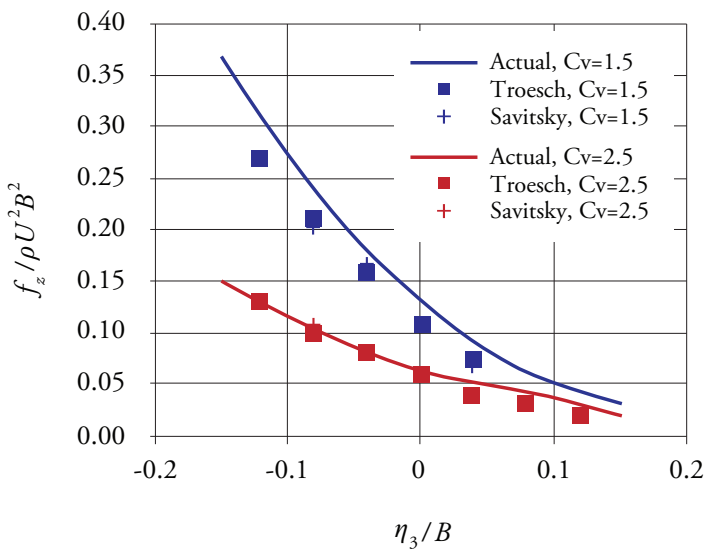

Fig. $15 . \mathrm{M}_{\mathrm{y}}$ vs. $\eta_{3} / \mathrm{B}$

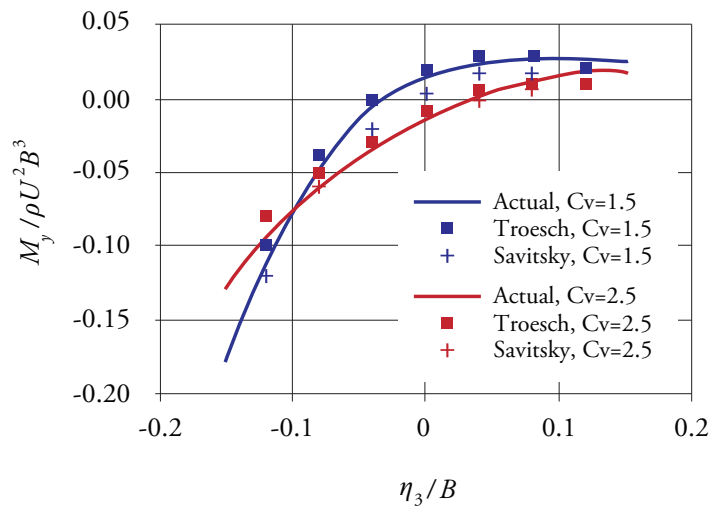

Fig. 16. $\mathrm{F}_{\mathrm{z}}$ vs. $\eta_{5} / \mathrm{B}$

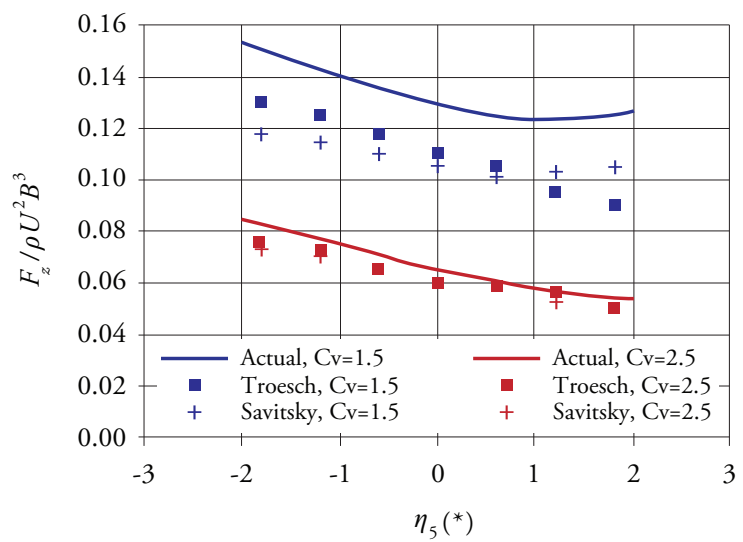

Figs. 18 and 19 show the critical condition that produces the inception of instability in the vertical plane for boats with $\beta=10^{\circ}$ and $\beta=20^{\circ}$; the results are compared with Celano (1998) and Savitsky (1964). The criteria for the instability is the pitch
Fig. 17. $\mathrm{M}_{\mathrm{y}}$ vs. $\eta_{5} / \mathrm{B}$

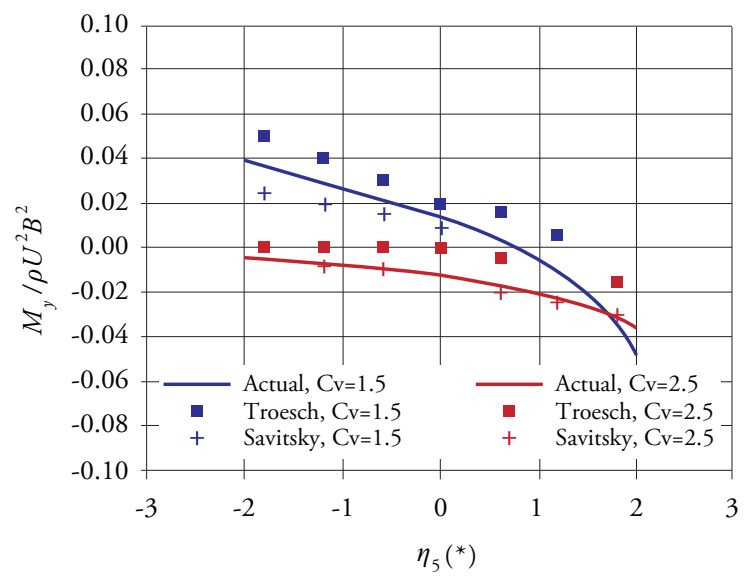

Fig. 18. $\theta_{\text {critical }}$ vs. $\mathrm{CL}, B=10^{\circ}$

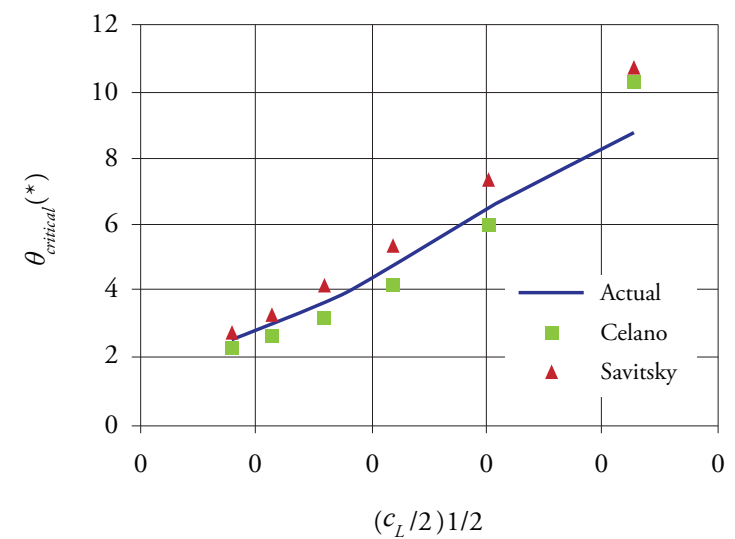

Fig. 19. $\theta_{\text {critical }}$ vs. CL, $B=20^{\circ}$

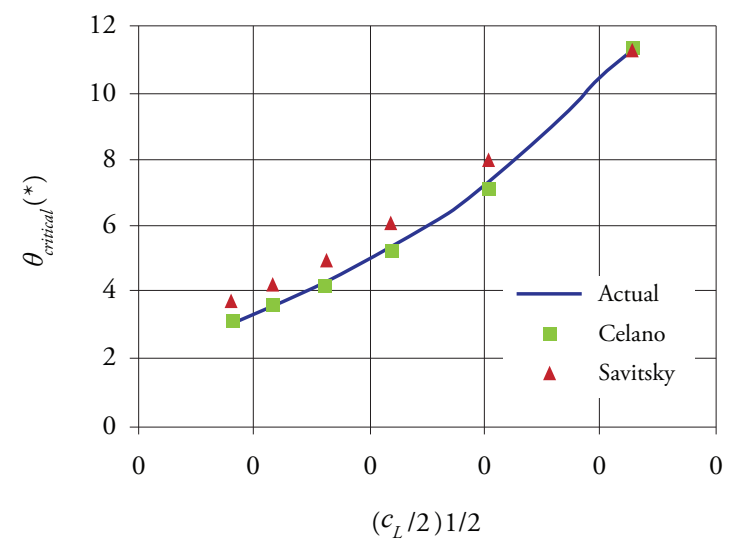

amplitude oscillation, $\eta_{50}>1^{\circ}$. The boat has the following conditions: $C_{\Delta}=0.394, k y y / B=1.25$ $V_{c d g} / B=0.4$ and $l / B=5$, where $k y y$ is the gyration radius. The value of Lcdg was changed to find the critical condition for each configuration. 


\section{Conclusions}

The Wagner model (1932) was extended for section with knuckle; force and pressure distribution were evaluated after the flow separation from the knuckle. The 2D dynamic impact was simulated; the results were compared with Peterson (1997) obtaining good agreement. The $2 \mathrm{D}$ impact was applied to a planing boat by the slender body theory and a dynamic model for planing hull in calm water was developed. The lift force and trim moment were calculated for ships in steady condition; the results obtained were compared with Savitsky (1964) and Troesch (1992). Critical conditions that cause the inception of porpoising were determined; the results are compared with Savitsky (1964) and Celano (1998) with good agreement.

\section{References}

ALGARÍN R. AND TASCÓN O. Hydrodynamic Modeling of Planing Boats with Asymmetry and Steady Condition, [on-line]. Avilable at: http://www.din.unina.it/HSMV\%20 2011\%20Proceedings/html/Papers/31.pdf. HSMV 2011, Naples, 2011.

ALGARIN R., BULA A.AND TASCÓN O. CFD modeling of 2D Asymmetric entry impact along with horizontal velocity, Ship Science \& Technology. n 9, Vol 5, 2011, p. 99-106.

CELANO, T. The prediction of Porpoising Inception for Modern Planing Craft. SNAME transaction,Vol. 106, 1998, pp. 269-292.
DEYZEN A. A nonlinear mathematical model of motions of a planing monohull in head sea, [online]. Avilable at: http://www.hiper08.unina. it/cd\%20hiper\%2008/HTML/Papers/16\%20 -\%20van\%20Deyzen.pdf. 2008.

PETERSON R., WYMAN D. AND FRANK, C. Drop Tests to Support Water-Impact and Planing Boat Dynamics Theory, Technical report CSS/TR-97/25, 1997

SAVITSKY, D. Hydrodynamic design of planning hulls, Marine Technology, nº, Vol 1, 1964, p71-96.

TROESCH A. On the hydrodynamics of Vertically oscillating Planning Hull, Journal of Ship Research, Vol 36, 1992, p317-331.

TVEITNES, T. Application of Added Mass theory in planing [Ph.D. Thesis]. Glasgow: University of Glasgow. Department of Naval Architecture and ocean engineering, 2001, 339p.

WAGNER, H. Über stoss - und Gleitvorgänge an der Oberfläshe von Flüssigkeiten. eitschrift für Angewandte Mathematik und Mechanik. August, No. 4, Vol. 12, 1932, p. 193-215.

ZARNICK E. A Nonlinear Mathematical Model of Motion of a planing boat in Regular Waves, Technical report DTNRDC-78/032, 1978. 